\title{
Renal dysfunction decreases specificity and overturns cutoff value of serum CC16 while prohibiting 7-day mortality prediction in diagnosing acute respiratory distress syndrome in intensive care unit.
}

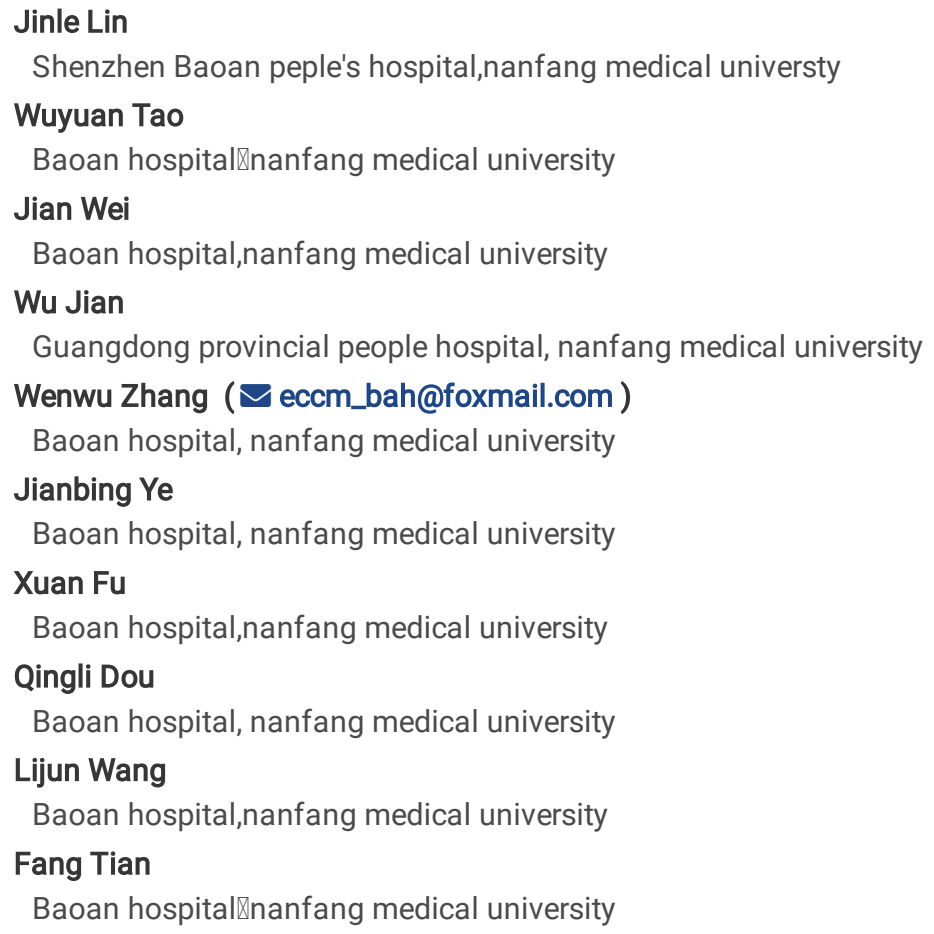

Keywords: Acute respiratory distress syndrome, Acute kidney injury, Chronic kidney injury, Biomarkers, Club cell protein 16 Posted Date: January 13th, 2020

DOI: https://doi.org/10.21203/rs.2.20735/v1

License: (c) This work is licensed under a Creative Commons Attribution 4.0 International License. Read Full License 


\section{Abstract}

Background: A contradictory tendency between occurrence of acute respiratory distress syndrome (ARDS) and serum club cell protein 16 (CC16) level, However, renal dysfunction (RD) separately raised serum CC16 in our current observation. The purpose of this study was to find the limitation caused by renal dysfunction in the diagnostic performance of CC16 on ARDS in intensive care unit (ICU) patients.

Method: We measured serum CC16 in 479 ICU patients. Patients were divided into six subgroups: control, acute kidney injury (AKI), chronic kidney dysfunction (CKD), ARDS, ARDS+AKI, and ARDS+CKD. The cutoff value, sensitivity and specificity of serum CC16 were assessed by receiver operating characteristic curves.

Result: Serum CC16 increased among the ARDS group when compared to the control group, which helps identify ARDS and predicts the outcome in patients with normal renal function. However, level of serum CC16 was similar among ARDS+AKI, ARDS+CKD, AIK and CKD groups. Consequently, when compare to AKI and CKD, specificity for diagnosing whether ARDS or ARDS with renal failure decreased from $86.62 \%$ to $2.82 \%$ or $81.70 \%$ to $2.12 \%$. Consistently, a cutoff value of $11.57 \mathrm{ng} / \mathrm{mL}$ was overturned from previously at $32.77 \mathrm{ng} / \mathrm{mL}$ or $33.72 \mathrm{ng} / \mathrm{mL}$. Moreover, its predictive value for mortality is prohibited before 7 day but works after 28 day.

Conclusion: Renal dysfunction limits the specificity, cutoff point, and predictive value at 7-day mortality of CC16 in diagnosing ARDS among ICU patients.

\section{Background}

Acute respiratory distress syndrome (ARDS) is an acute lung disease with high mortality and morbidity in intensive care units (ICUs). No effective interventions have been established for its treatment due to the limited exploration into the physiological processes. Early correct diagnosis is crucial to determine effective management. However, traditional methods, including $\mathrm{PaO}_{2} / \mathrm{FiO}_{2}$ and X-ray mentioned in the Berlin definition, actually fall behind the progression of ARDS. Consequently, more than 20 potential biomarkers have been used for the diagnosis and prediction of ARDS in current studies[1], including the club cell protein (CC16).

CC16 is produced by club cells and was first described by the German anatomist Max Clara in 1937 [2]. The bronchial epithelium consists of $80 \%$ club cells, such as basal or nonciliated secretory cells, particularly in the distal bronchia[3]. According to previous studies, CC16, as the most abundant secretory protein found in the surface fluids of the airways, was revealed to play an important role in the maintenance and repair of lung airways[4], and it is a potential biomarker of pulmonary injury caused by inhaled ozone, chlorine, and lipopolysaccharides[2].

Five previous studies have evaluated the change of CC16 in ARDS patients. However, the results remain controversial. First, in 2006 a prospective multicenter observational study of 78 critical care patients conducted by the Quebec Critical Care Network found an increase of serum CC16 levels were linked with the onset and negative outcomes of ARDS patients[5]. In addition, Determann et al. discovered increased plasma levels of CC16 in 22 ventilator-associated pneumonia patients who developed ARDS. They found a better diagnostic capacity of CC16 at the cutoff point of $30 \mathrm{ng} / \mathrm{ml}$ compared to surfactant Protein D, Krebs von den Lungen, and soluble receptor for advanced glycation end products. It is interesting that increases of CC16 were seen prior to a diagnosis of ARDS [6]. Wutzler et al. further revealed increases of serum CC16 levels accompanied with secondary respiratory complications in patients with multiple injuries[7]. However, Kropski et al. found lower median plasma CC16 levels in ARDS patients than in those with cardiogenic pulmonary edema ( $22 \mathrm{ng} / \mathrm{ml} \mathrm{vs.} 55 \mathrm{ng} / \mathrm{ml}$ ) [8]. Furthermore, Ware et al. indicated that lower levels of CC16 $(9.2 \mathrm{ng} / \mathrm{ml})$ might help clinicians distinguish ARDS patients from sepsis patients[9]. From the above studies, a contradictory tendency indicated that not only ARDS but other factors influenced serum CC16 levels.

Previously, we found that increasing serum CC16 levels (cutoff point at $\geq 33.3 \mathrm{ng} / \mathrm{mL}$ ) predicted the onset of ARDS and was negatively correlated with the $\mathrm{PaO}_{2} / \mathrm{FiO}_{2}$ ratio among ARDS patients[10]. However, renal dysfunction (RD) separately raised serum CC16 in our current observation. In the present study, we retrospectively evaluated the limitation caused by RD in the diagnostic performance of serum CC16 on ARDS in ICU patients.

\section{Materials And Methods}

\subsection{Study population}

During March 2013 and March 2015, a portion of patients admitted into our ICU were enrolled in our study. The following was the criteria for inclusion for further analysis: 1) patient age over 18 and under 75;2) ICU stay of more than 12 hours; 3) blood samples were collected less than 6 hours after admission; and 4) diagnosis was clarify before discharge. One of above criterion was not fit when they were not excluded. The Institutional Human Ethics Committee of Baoan Hospital, Nanfang Medical University approved the study protocols employed in this observational study. Written informed consent was obtained from each subject or their legal guardians. 


\subsection{Data collection and laboratory examination}

Values at baseline, including age, gender, blood pressure, body temperature, respiratory rate, heart rate, shock index, and $\mathrm{PaO} / 2 \mathrm{FiO} \mathrm{O}_{2}$ ratio, were collected within 3 hours after admission into the ICU. Seven-day mortality was recorded for all enrolled patients.

Determination of N-terminal of the prohormone brain natriuretic peptide (NT-proBNP), albumin, and serum creatinine were synchronously performed within 3 hours after admission.

All above data were compiled in a Microsoft Office Excel 2003 spreadsheet (Microsoft Corp., Seattle, WA, USA) for subsequent analysis.

\subsection{Diagnosis criteria}

ARDS diagnosis needed to fit the Berlin definition[11]: 1) acute course, less than 7 days; 2) bilateral opacities consistent with pulmonary edema, as detected by CT or X-ray; and 3) $\mathrm{PaO}_{2} / \mathrm{FiO}_{2}$ ratio less than $300 \mathrm{mmHg}$, with ventilation support (Positive End Expiratory Pressure or Continuous Positive Airway Pressure $\geq 5 \mathrm{mmH} 2 \mathrm{O}$ ).

Acute kidney injury (AKI) or chronic kidney disease (CKD) needed to fit the clinical practice guidelines of the $2012 \mathrm{Kidney}$ Disease Improving Global Outcomes organization[12]. AKI is defined as an increase in creatinine of $\geq 0.3 \mathrm{mg} / \mathrm{dL}(26.4 \mathrm{umol} / \mathrm{mL}) \mathrm{within} 48 \mathrm{hours}$ or $\geq 50 \%$ above baseline, known or presumed to have occurred within the prior 7 days. CKD is defined as an estimated glomerular filtration rate (Estimated Glomerular Filtration Rate) $<60 \mathrm{~mL} / \mathrm{min} \cdot 1.73 \mathrm{~m}^{2}$ for more than 3 months.

\subsection{Subgroup division}

Two senior physicians divided the subjects into six subgroups after retrospectively reviewing the diagnosis for each subject based on their clinical conditions within 3 hours after admission: 1) control group: ICU patients without ARDS or RD; 2) AKI group: AKI patients without ARDS;

3) CKD group: CKD patients without ARDS; 4) ARDS group: ARDS patients without RD; 5) ARDS + AKI group: ARDS patients with AKl; and 6) ARDS + CKD group: ARDS patients with CKD.

\subsection{Measurement of serum CC16}

Blood samples were immediately centrifuged at $3000 \mathrm{rpm}$ for $10 \mathrm{~min}$, and the serum was stored at $-60{ }^{\circ} \mathrm{C}$ prior to analysis. The CC16 concentration was determined using an enzyme-linked immunosorbent assay kit (R\&D Systems, Minneapolis, MN, USA) following the manufacturer's instructions. A laboratory staff member who had not been provided with the related clinical data performed each assay blindly and in duplicate.

\subsection{Statistical analysis}

Data were presented as the mean \pm standard deviation or median (interquartile range) as indicated. Student's t test or Mann-Whitney $U$ test was used for comparisons between the groups when appropriate based on the normality of the data. Categorical data were compared using the $\chi^{2}$ or Kruskal-Wallis test. Differences among more than three subgroups were assessed using one-way analysis of variance. Linear correlations among $\mathrm{CC} 16, \mathrm{PaO}_{2} / \mathrm{FiO}_{2}$ ratios, albumin, serum creatinine, and NT-proBNP were calculated using the Pearson linear correlation model. Receiver operating characteristic (ROC) curves were introduced to assess the optimal cutoff values, sensitivity, and specificity. A P-value< 0.05 was considered statistically significant. Statistical analyses were performed using the SPSS software package (version 20.0; SPSS Inc., Chicago, IL, USA). Statistical graphs were created using GraphPad Prism 3.0 software (GraphPad Software Inc., La Jolla, CA, USA).

\section{Results}

\subsection{Patient baseline characteristics}

A total of 479 critical care patients were recruited into our study, including 230 cases in the control group, 45 cases in the AKI group, 47 cases in the CKD group, 83 cases in the ARDS groups, 61 cases in the ARDS+AKI group, and 13 cases in the ARDS+CKD group. Lower blood pressure along with a higher incidence of pneumonia and sepsis were found in the ARDS group and the ARDS+AKI group compared to the control group. However, higher blood pressure along with a higher proportion of cardiogenic pulmonary edema were discovered in the CKD group and the ARDS+CKD group compared to the control group (Table 1).

\subsection{Serum CC16 levels in six subgroups}

Serum CC16 was increased among the ARDS group compared to the control group $(47.78 \pm 19.92 \mathrm{ng} / \mathrm{ml} \mathrm{vs}$. $22.23 \pm 13.28 \mathrm{ng} / \mathrm{ml}, P=0.001)$. However, despite having higher levels of serum CC16 than the two above groups, the following groups all had similar levels to each other: the ARDS+AKI group $(64.89 \pm 20.47 \mathrm{ng} / \mathrm{ml})$, the ARDS+CKD group $(72.21 \pm 18.63 \mathrm{ng} / \mathrm{ml})$, the AKI group (59.77 $\pm 26.76 \mathrm{ng} / \mathrm{ml})$, and the CKD $\mathrm{group}$ (62.77 $\pm 25.11 \mathrm{ng} / \mathrm{ml}$ ) (Figure 1). 
We constructed ROC curves to evaluate the diagnostic performance of serum CC16 in critical care patients (Table 2). Although different schemes of ROC curves showed a similar sensitivity, when renal dysfunction presented with baseline characteristics, specificity for diagnosing whether it was ARDS or ARDS with a renal condition (AKI or CKD) decreased from $86.62 \%$ to $2.82 \%$ (ROC.1 vs. ROC.3) or $81.70 \%$ to $2.12 \%$ (ROC.2 vs. ROC.4). Consistently, an opposite cutoff value of $11.57 \mathrm{ng} / \mathrm{ml}$ was found, a decrease from the previous value of $32.77 \mathrm{ng} / \mathrm{ml}$ or $33.72 \mathrm{ng} / \mathrm{ml}$.

\subsection{Correlation between serum CC16 levels and other clinical parameters in six subgroups}

Compared to the control group, a higher concentration of serum CC16, accompanied with a lower value on the PaO2/FiO2 and albumin, was found in the ARDS group. However, decreased renal function in the AKI, CKD, ARDS+AKI, and ARDS+CKD groups was related to a consistent increase of serum CC16, NT-proBNP, and creatinine compared to the control and ARDS groups. Furthermore, Pearson correlation analysis showed that serum CC16 levels were positively correlated with creatinine ( $r=0.461$, Fig. 3A) and NT-proBNP ( $r=0.400$, Fig.3B) but negatively correlated with $\mathrm{PaO}_{2} / \mathrm{FiO}_{2}$ ( $r=0 .-277$, Fig. 3C) and albumin ( $r=-0.193$, Fig.3D).

\subsection{Relationship serum CC16 and outcomes of ICU patients}

Higher serum CC16 in all groups presented in the non-survival group with 7-day mortality (68 cases, 14.19\%) and 28-day mortality (121 cases, $25.26 \%)$ than for those in the survival group $(54.99 \pm 25.74 \mathrm{ng} / \mathrm{mL}$ vs. $38.57 \pm 25.76 \mathrm{ng} / \mathrm{mL} ; 51.01 \pm 25.89 * \mathrm{ng} / \mathrm{mL} \mathrm{vs}$. $37.49 \pm 25.67 \mathrm{ng} / \mathrm{mL})$. However, in the subgroups analysis, renal dysfunction affected the prediction value at 7-day mortality at a similar level of serum CC16 among the AKI group, CKD group, ARDS+AKI group, and ARDS+CKD group (Table 4).

\section{Discussion}

Consistent with our previous study, increasing serum CC16 helped clinicians identify ARDS in critical care patients with normal renal function. However, renal dysfunction, whether AKI or CKD, synchronously raised serum CC16, resulting in decreased specificity of serum CC16 and overturning the opposite cutoff points. Additionally, its predictive value of the outcome at 7 days disappeared if the patients had renal dysfunction.

The increasing serum CC16 not only depends on the transportation from the bronchoalveolar lavage fluid but also its clearance in the kidney. Several past studies have explored its value in monitoring the permeability of the blood-air barrier, which has a 1000-times concentration gradient constituted from bronchoalveolar lavage fluid $(0.5-1.5 \mathrm{mg} / \mathrm{L})$ and serum $(10-15 \mathrm{ng} / \mathrm{ml})$ in healthy nonsmokers. Therefore, CC16 has been proved in patents with multiple etiologies, such as chronic exposure to toxicants or severe air pollution[13-15]. However, CC16 has not been responsively synthesized, as evidenced by the negative correlation between serum CC16 and albumin in this study, and synthesis of albumin in response to ARDS can be rapidly reduced until the vascular compartment is repaired[16]. Furthermore, rapid renal clearance of serum CC16 with a half-life of approximately 2-3 hours was previously found to occur via cubilin and/or megalin receptor-mediated endocytosis in the proximal tubule epithelial cells[17]. Andersson et al. found that excretion of CC16 was related to the severity of renal damage, measured by acute dimercaptosuccinic acid scintigraphy. Another clinical study indicated that CC16 can possibly predict creatinine clearance [18]. In addition, in vivo experiments have shown a significant increase in serum CC16 levels of 400 over the basal value after paraquat-induced lung injury[19]; in that study, the elevation of CC16 was mainly determined by the degree of renal impairment. Actually, two above mentioned conditions will increase serum CC16 in critical care patients: destruction of permeability in blood-air barrier and dysfunction of renal clearance[20].

Decreased renal function has been proven to be associated with elevation NT-proBNP in a previous study[21].In our study, worsening renal condition, whether AKI, CKD, ARDS + AKI, or ARDS + CKD, synchronously raised not only CC16 but also NT-proBNP and creatinine. The positive relationship between these renal conditions and CC16, creatinine, and NT-proBNP indicated a higher prevalence of cardiac pulmonary edema in the control group in a study by Kropski et al[8], which also demonstrated baseline characteristics of cardiac pulmonary edema in the CKD or ARDS + CKD group. Our analysis demonstrated that presentation of renal dysfunction weakened the specificity and received an opposite cutoff value of serum CC16 for the diagnosis of ARDS, which might have mostly contributed to the past contradictory gap.

Although CC16 levels were not associated with a one-month clinical respiratory prognosis in a large randomized trial investigation $(\mathrm{n}=1200)$ [22], we found higher serum CC16 still predicted a bad outcome in ICU patients with renal function before 28 days. However, if patients have renal failure, this predictive value is prohibited before 7 days but works after 28 day. In our opinion, a decrease in the serum CC16 might represent a good prognosis, as this could be a sign of repair on the alveolar-capillary barrier in critical care patients, though this needs to be proven through further investigation with adequate data. 
Moreover, the biological role of a CC16 increase in the ARDS process is not clear. As an immunoregulatory protein, CC16 executes an antiinflammatory function by inhibiting phospholipase A2 activation and promoting the expression of inflammatory cascades (IL-1b, IL-8, et al.), $\mathrm{TH} 2$ cell differentiation, and the migration of neutrophils and monocytes[23, 24]. Consistent with these studies, Pang demonstrated that recombinant rat CC16 protein inhibits LPS-induced MMP-9 expression and the production of pro-inflammatory cytokines via NF-KB pathway in model of tracheal epithelial cells and RAW264.7 macrophages[25, 26]. She suggested that exogenous supplementation of recombinant CC16 ameliorates cigarette smoke-induced lung inflammation in a murine disease model of chronic obstructive pulmonary disease[27]. Further exploration is needed of CC16's function for critical care patients in the future.

The present study did have a few limitations. First, as a comprehensive ICU, we only enrolled critical care patients but no healthy patients who may have received potential affecting interventions. Although previous studies have revealed a relatively stable median CC16 level in normal controls $(5-7 \mathrm{ng} / \mathrm{ml})$, the median CC16 value of critical care patients in our control group appeared to be higher ( $22.23 \pm 13.28 \mathrm{ng} / \mathrm{ml})$, probably because clinical conditions such as mechanical ventilation or primary graft dysfunction might promote the production of CC16[28, 29]. This could have led to an unavoidable selection bias. However, the selection of ICU patients rather than healthy individuals as the control for comparison is clinically meaningful for accurately diagnosing ARDS in the ICU. Second, we only monitored serum CC16 levels on admission and lacked a parallel comparison with other promising biomarkers. Additional valuable clinical investigation related to comparing the CC16 value with other biomarkers for critical care patients needs to be explored in future research with a broader range of patients. Thus, the diagnostic and prognostic values of CC16 in ARDS will require further investigation in a prospective study with a larger sample size.

\section{Conclusion}

We reported increasing serum CC16 can help identify ARDS and predict the outcome in critical care patients with normal renal function. However, renal dysfunction, whether AKI or CKD, synchronously raises serum CC16, while results in a decrease in its specificity and overturns the optimal cutoff points. Moreover, its predictive value is prohibited before 7 days but works after 28 day.

\section{List Of Abbreviations}

AKI, Acute kidney injury; ARDS, acute respiratory distress syndrome; CC16, club cell protein 16; CKD, Chronic kidney dysfunction; ICU, intensive care unit; MAP, mean arterial pressure; NT-proBNP, N-Terminal prohormone brain natriuretic peptide; RD, Renal dysfunction; ROC, Receiver operating characteristic curves; SBP, systolic blood pressure.

\section{Declarations}

\section{Ethics approval and consent to participate}

The Institutional Human Ethics Committee of Baoan Hospital, Nanfang Medical University approved the study protocols employed in this observational study. Written informed consent was obtained from each subject or their legal guardians.

\section{Consent for publication.}

This paper has not been published elsewhere in whole or in part. All authors have read and approved the content, and agree to submit it for consideration for publication in your journal.

\section{Availability of data and materials}

The datasets used and/or analyzed during the current study are available

from the corresponding author on reasonable request.

\section{Competing interests}

The authors declare no conflict of interest.

\section{Funding}

This work was supported through funding from the Science, Technology, \& Innovation Commission of Shenzhen Municipality (Grant Nos. JCYJ20170307094345589 and JCYJ20180305123707368) and National Natural Science Foundation of China (Grant Nos.81970012).

\section{Authors' contributions}


Jinle Lin, Wu Jian and Wenwu Zhang participated in the question conception, data analysis, and manuscript draft preparation. Wuyuan Tao, Jianbing Ye, Shiyong Zeng and Xuan Fu abstracted the data collection and Formal Analysis. Qingli Dou, Lijun Wang, and Fang Tian provided critical appraisals of the study and helped with the development of the study question.

\section{Acknowledgments}

We thank all the investigators for their excellent assistances in this clinical research.

\section{References}

[1]. Garcia-Laorden MI, Lorente JA, Flores C, et al. Biomarkers for the acute respiratory distress syndrome: how to make the diagnosis more precise. Ann Transl Med. 2017;5(14):283.

[2]. Wong AP, Keating A, Waddell TK. Airway regeneration: the role of the Clara cell secretory protein and the cells that express it. Cytotherapy. 2009;11(6):676-87.

[3]. Boers JE, Ambergen AW, Thunnissen FB. Number and proliferation of basal and parabasal cells in normal human airway epithelium. Am J Respir Crit Care Med. 1998;157(6 Pt 1):2000-6.

[4]. Broeckaert F, Clippe A, Knoops B, et al. Clara cell secretory protein (CC16): features as a peripheral lung biomarker. Ann N Y Acad Sci. 2000;923:68-77.

[5]. Lesur $\mathrm{O}$, Langevin S, Berthiaume $\mathrm{Y}$, et al. Outcome value of Clara cell protein in serum of patients with acute respiratory distress syndrome. Intensive Care Med. 2006;32(8):1167-74.

[6]. Determann RM, Millo JL, Waddy S, et al. Plasma CC16 levels are associated with development of ALI/ARDS in patients with ventilatorassociated pneumonia: a retrospective observational study. BMC Pulm Med. 2009;9:49.

[7]. Wutzler S, Backhaus L, Henrich D, et al. Clara cell protein 16: A biomarker for detecting secondary respiratory complications in patients with multiple injuries. J Trauma Acute Care Surg. 2012;73(4):838-42.

[8]. Kropski JA, Fremont RD, Calfee CS, et al. Clara Cell Protein (CC16), a Marker of Lung Epithelial Injury, Is Decreased in Plasma and Pulmonary Edema Fluid From Patients With Acute Lung Injury. Chest. 2009;135(6):1440-7.

[9]. Ware LB, Koyama T, Zhao Z, et al. Biomarkers of lung epithelial injury and inflammation distinguish severe sepsis patients with acute respiratory distress syndrome. Crit Care. 2013;17(5):R253.

[10]. Lin J, Zhang W. Diagnostic and prognostic values of Club cell protein 16 (CC16) in critical care patients with acute respiratory distress syndrome. J Clin Lab Anal. 2018;32(2):e22262.

[11]. Force ADT, Ranieri VM, Rubenfeld GD, et al.Acute respiratory distress syndrome: the Berlin Definition. JAMA. 2012;307(23):2526-33.

[12]. Levin A, Stevens PE, Bilous RW, et al. Kidney disease: Improving global outcomes (KDIGO) CKD work group. KDIGO 2012 clinical practice guideline for the evaluation and management of chronic kidney disease. Kidney International Supplements. 2013;3(1):1-150.

[13]. Hantson P, Bernard A, Hermans C. Kinetics and determinants of the changes of $\mathrm{CC} 16$, a lung secretory protein in a rat model of toxic lung injury. Clin Toxicol (Phila). 2008;46(3):230-8.

[14]. Provost EB, Chaumont A, Kicinski M, et al. Serum levels of club cell secretory protein (Clara) and short- and long-term exposure to particulate air pollution in adolescents. Environment international. 2014;68:66-70.

[15]. St Helen G HN, Balmes JR, Hall DB, et al. Utility of urinary Clara cell protein (CC16) to demonstrate increased lung epithelial permeability in non-smokers exposed to outdoor secondhand smoke. Journal of Exposure Science \& Environmental Epidemiology. 2013;23(2).

[16]. Ishida S, Hashimoto I, Seike T, et al. Serum albumin levels correlate with inflammation rather than nutrition supply in burns patients: a retrospective study. J Med Invest. 2014;61(3-4):361-8.

[17]. Amsellem S, Gburek J, Hamard G, et al. Cubilin is essential for albumin reabsorption in the renal proximal tubule. J Am Soc Nephrol. 2010;21(11):1859-67.

[18]. Andersson L, Preda I, Hahn-Zoric M, et al. Urinary proteins in children with urinary tract infection. Pediatr Nephrol. 2009;24(8):1533-8. 
[19]. Hantson P, Weynand B, Doyle I, et al. Pneumoproteins as markers of paraquat lung injury: a clinical case. J Forensic Leg Med. 2008;15(1):48-52.

[20]. Mekontso Dessap A, Ware LB, Bagshaw SM. How could biomarkers of ARDS and AKI drive clinical strategies? Intensive care medicine. 2016;42(5):800-2.

[21]. Potter JM, Simpson AJ, Kerrigan J, et al. The relationship of plasma creatinine (as eGFR) and high-sensitivity cardiac troponin and NTproBNP concentrations in a hospital and community outpatient population. Clinical Biochemistry. 2017;50(15):813-5.

[22]. Jensen JS, Itenov TS, Thormar KM, et al. Prediction of non-recovery from ventilator-demanding acute respiratory failure, ARDS and death using lung damage biomarkers: data from a 1200-patient critical care randomized trial. Ann Intensive Care. 2016;6(1):114.

[23]. Yoshikawa S, Miyahara T, Reynolds SD, et al. Clara cell secretory protein and phospholipase A2 activity modulate acute ventilatorinduced lung injury in mice. J Appl Physiol. 2005;98(4):1264-71.

[24]. Johansson S, Wennergren G, Aberg N, et al. Clara cell 16-kd protein downregulates $\mathrm{T}(\mathrm{H}) 2$ differentiation of human naive neonatal T cells. J Allergy Clin Immunol. 2007;120(2):308-14.

[25]. Pang M, Wang H, Bai JZ, et al. Recombinant rat CC16 protein inhibits LPS-induced MMP-9 expression via NF-kappaB pathway in rat tracheal epithelial cells. Exp Biol Med (Maywood). 2015;240(10):1266-78.

[26]. Pang M, Yuan Y, Wang D, et al. Recombinant CC16 protein inhibits the production of pro-inflammatory cytokines via NF-kB and p38 MAPK pathways in LPS-activated RAW264.7 macrophages. Acta biochimica et biophysica Sinica. 2017;49(5):435-43.

[27]. Pang M, Liu H-Y, Li T, et al. Recombinant club cell protein 16 (CC16) ameliorates cigarette smoke-induced lung inflammation in a murine disease model of COPD. Molecular medicine reports. 2018;18(2):2198-206.

[28]. Lesur O, Hermans C, Chalifour JF, et al. Mechanical ventilation-induced pneumoprotein CC-16 vascular transfer in rats: effect of KGF pretreatment. Am J Physiol Lung Cell Mol Physiol. 2003;284(2):L410-9.

[29]. Sarafidis K, Stathopoulou T, Agakidou E, et al. Comparable effect of conventional ventilation versus early high-frequency oscillation on serum CC16 and IL-6 levels in preterm neonates. Journal of Perinatology. 2011;31(2):104-11.

\section{Tables}

Table 1. Baseline characteristics of patients at admission 


\begin{tabular}{|c|c|c|c|c|c|c|}
\hline Items & Controls group ( $n=230)$ & $\begin{array}{l}\text { AKI group } \\
\quad(n=45)\end{array}$ & $\begin{array}{l}\text { CKD group } \\
\quad(n=47)\end{array}$ & $\begin{array}{l}\text { ARDS group } \\
\quad(n=83)\end{array}$ & $\begin{array}{l}\text { ARDS+AKI group } \\
\quad(n=61)\end{array}$ & $\begin{array}{c}\text { ARDS+CKD group } \\
(n=13)\end{array}$ \\
\hline Gender, male, $n(\%)$ & $135(58.7)$ & $33(73.3)$ & $24(51.1)$ & $48(57.8)$ & $45(73.8)$ & $8(61.5)$ \\
\hline female, $n(\%)$ & $95(41.3)$ & $12(26.7)$ & $23(48.9)$ & $35(42.2)$ & $16(26.2)$ & $5(38.5)$ \\
\hline Age, years & $49.1 \pm 18.5$ & $54.1 \pm 18.1$ & $64.3 \pm 14.5$ & $52.4 \pm 20.4$ & $57.0 \pm 18.7$ & $57.4 \pm 20.4$ \\
\hline Body temperature, ${ }^{\circ} \mathrm{C}$ & $36.8 \pm 0.9$ & $36.7 \pm 0.8$ & $36.6 \pm 0.7$ & $37.1 \pm 0.9$ & $36.1 \pm 4.7$ & $36.8 \pm 1.2$ \\
\hline Heart rate, per min & $98.8 \pm 24.5$ & $104.4 \pm 26.1$ & $89.9 \pm 27.3$ & $121.6 \pm 103.4^{*}$ & $114.1 \pm 26.8^{*}$ & $112.9 \pm 28.4$ \\
\hline Systolic blood pressure, $\mathrm{mmHg}$ & $131.6 \pm 24.2$ & $127.8 \pm 31.6$ & $150.9 \pm 36.2$ & $124.5 \pm 27.2^{*}$ & $117.9 \pm 31.9^{*}$ & $141.3 \pm 23.1$ \\
\hline Diastolic blood pressure, $\mathrm{mmHg}$ & $80.59 \pm 16.7$ & $76.6 \pm 23.0$ & $78.5 \pm 21.7$ & $75.8 .7 \pm 17.14$ & $70.93 \pm 22.4$ & $77.9 \pm 17.504$ \\
\hline Mean arterial pressure, $\mathrm{mmHg}$ & $97.5 \pm 18.1$ & $93.7 \pm 24.3$ & $102.6 \pm 25.0$ & $92.1 \pm 19.2^{*}$ & $86.6 \pm 23.7^{*}$ & $100.3 \pm 17.59$ \\
\hline Shock index & $0.78 \pm 0.26$ & $0.89 \pm 0.45$ & $0.61 \pm 0.20^{\#}$ & $1.00 \pm 0.69^{*}$ & $1.02 \pm 0.34^{*}$ & $0.83 \pm 0.29^{\#}$ \\
\hline Pneumonia, $n(\%)$ & $57(24.8)$ & $7(15.6)$ & $13(27.7)$ & $71(85.5)^{*}$ & $45(73.8)^{*}$ & $12(92.3)$ \\
\hline Sepsis, $n(\%)$ & $14(6.1)$ & $11(24.4)$ & $5(10.6)$ & $18(21.7)^{*}$ & $26(42.6)^{*}$ & $3(23.1)$ \\
\hline $\mathrm{CPE}$ & $4(1.7)$ & $4(8.9)$ & $13(27.7)^{\#}$ & $2(2.4)$ & $5(8.2)$ & $7(53.8)^{\#}$ \\
\hline
\end{tabular}

Note: Data are analyzed using Student's t test or $\chi 2$ test. AKI, acute kidney injury; CKD, chronic kidney disease; ARDS, acute respiratory distress syndrome; CPE, cardiogenic pulmonary edema; *: Significant difference between the ARDS group or ARDS+AKI group and control group, $P<0.05$; \#: Significant difference between CKD group or ARDS+CKD group and control group, $P<0.05$.

Table 2. Receiver operating characteristic (ROC) curves of serum club cell protein 16 for diagnosis of acute respiratory distress syndrome (ARDS) in different schemes 


\begin{tabular}{|c|c|c|c|c|c|}
\hline Scheme & AUC & SD & Sensibility & Specificity & Cutoff \\
\hline ROC.1 & 0.868 & 0.023 & $81.70 \%$ & $81.74 \%$ & 32.77 \\
\hline ROC.2 & 0.909 & 0.016 & $86.62 \%$ & $83.48 \%$ & 33.72 \\
\hline ROC.3 & 0.341 & 0.041 & $98.78 \%$ & $2.82 \%$ & 11.57 \\
\hline ROC.4 & 0.456 & 0.038 & $98.72 \%$ & $2.12 \%$ & 11.57 \\
\hline ROC.5 & 0.780 & 0.021 & $87.89 \%$ & $61.81 \%$ & 32.77 \\
\hline
\end{tabular}

Note: ROC, receiver operating characteristic; AUC, area under the curve; SD, standard deviation;AKI, acute kidney injury; CKD, chronic kidney disease; ARDS, acute respiratory distress syndrome. ${ }^{*} P<0.05$

ROC.1 in control group vs. ARDS group;

ROC.2 in control group vs. ARDS group, ARDS+AKD group, and ARDS+CKD group;

ROC.3 in AKI group and CKD group vs. ARDS group;

ROC.4 in AKI group and CKD group vs. ARDS group, ARDS+AKD group, and ARDS+CKD group;

ROC.5 in control group, AKI group and CKD group vs. ARDS group, ARDS+AKD group and ARDS+CKD group.

Table 3. Serum CC16 and other clinical parameters in five subgroups

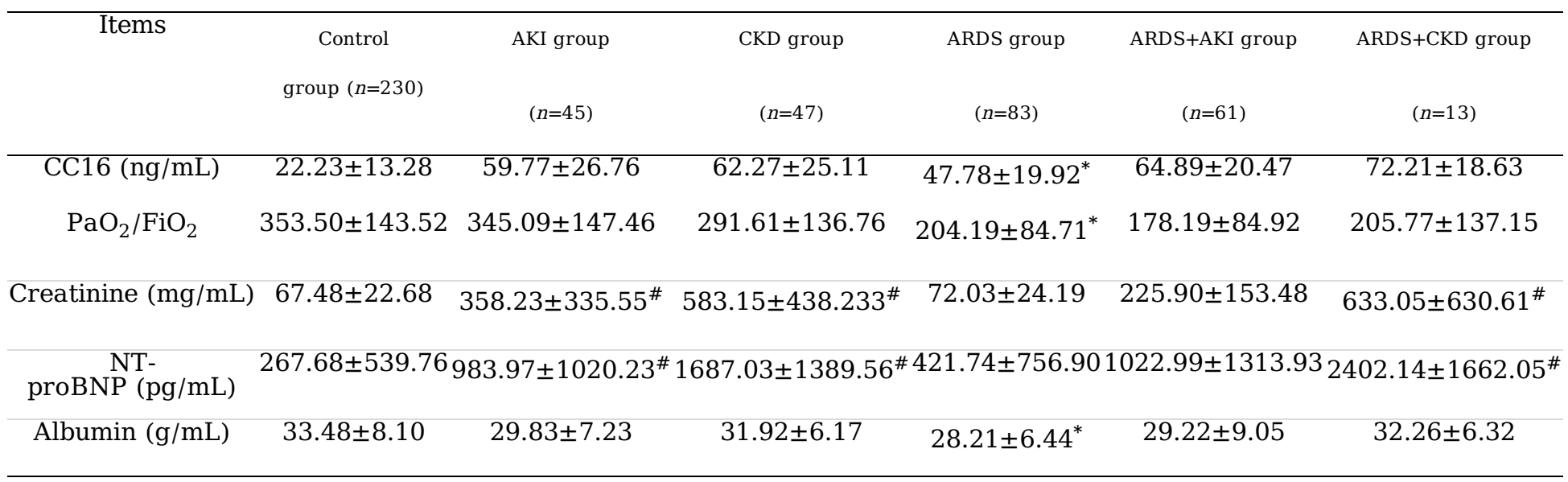

Note: CC16, club cell protein 16; NT-proBNP, N-terminal of the prohormone brain natriuretic peptide; AKI, acute kidney injury; CKD, chronic kidney disease; ARDS, acute respiratory distress syndrome;*: Significant difference value between the ARDS group and control group; ": Significant difference value in the AKI group, CKD group, ARDS+AKI group, and ARDS+CKD group compared to the control group or ARDS group.

Table 4. Relationship between serum CC16 and outcome of intensive care unit (ICU) patients 


\begin{tabular}{|c|c|c|c|c|}
\hline \multicolumn{2}{|c|}{ 7-day mortality, $n$ (\%) } & 18 (7.8) vs. $17(20.5)$ & 9 (20.0) and 5 (10.6) vs. 17 (27.9) and 2 (15.4) & $68(14.19)$ \\
\hline \multirow[t]{2}{*}{$\mathrm{CC} 16(\mathrm{ng} / \mathrm{mL})$} & Non-survival group & $40.27 \pm 22.61 *$ & $70.41 \pm 19.20$ & $54.99 \pm 25.74^{\star}$ \\
\hline & Survival group & $27.57 \pm 18.05$ & $61.58 \pm 24.28$ & $38.57 \pm 25.76$ \\
\hline \multicolumn{2}{|c|}{ 28-day mortality, n (\%) } & 32 (13.9) vs.33 (39.8) & 15 (33.3) and 11 (23.4) vs. 27 (44.3) and 3 (23.1) & $121 \square 25.26 \square$ \\
\hline \multirow[t]{2}{*}{$\mathrm{CC} 16(\mathrm{ng} / \mathrm{mL})$} & Non-survival group & $37.16 \pm 20.62 *$ & $66.99 \pm 22.04^{*}$ & $51.01 \pm 25.89^{\star}$ \\
\hline & Survival group & $26.88 \pm 18.01$ & $61.42 \pm 24.27$ & $37.49 \pm 25.67$ \\
\hline
\end{tabular}

Note: CC16, club cell protein 16; AKI, acute kidney injury; CKD, chronic kidney disease; ARDS, acute respiratory distress syndrome;* significant difference value between Non-survival group and Survival group; $\mathrm{P}<0.05$.

Figures

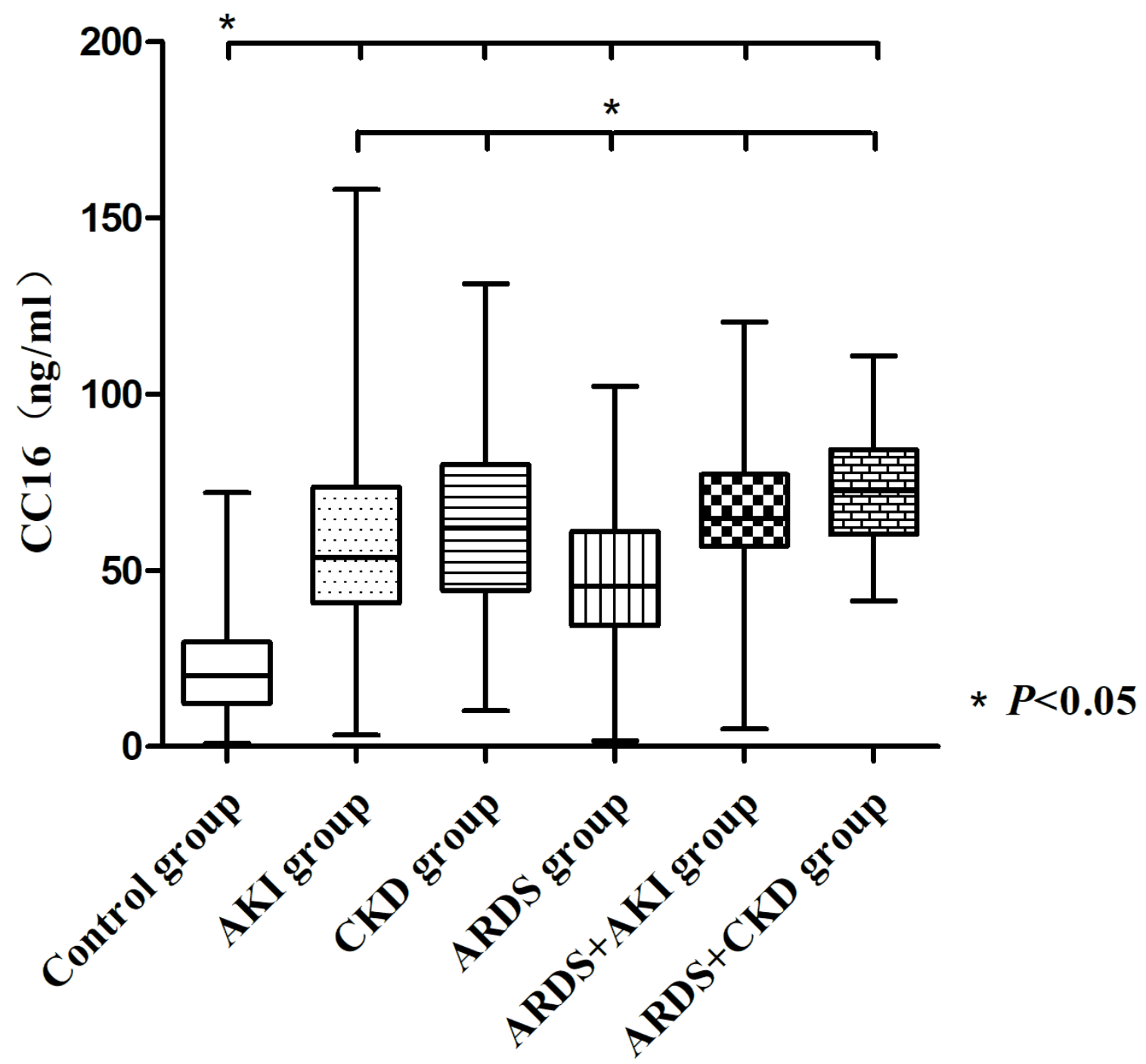

Figure 1 
Comparison of the serum CC16 levels between the control group, AKI group, CKD group, ARDS group, ARDS+AKI group, and ARDS+CKD group. *:P-value<0.05.

ROC.1

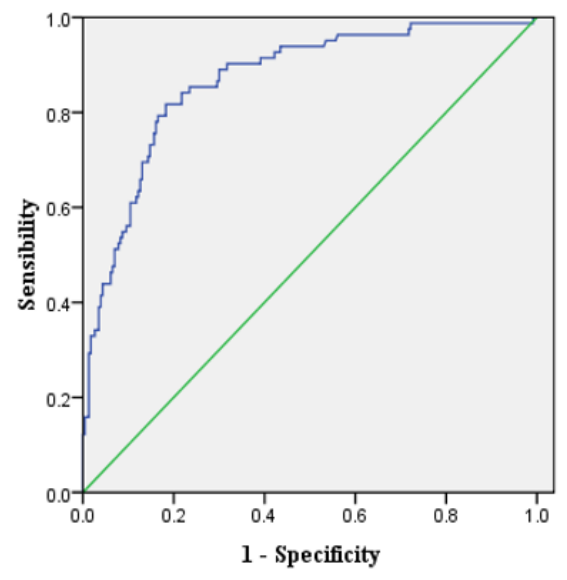

\section{ROC.3}

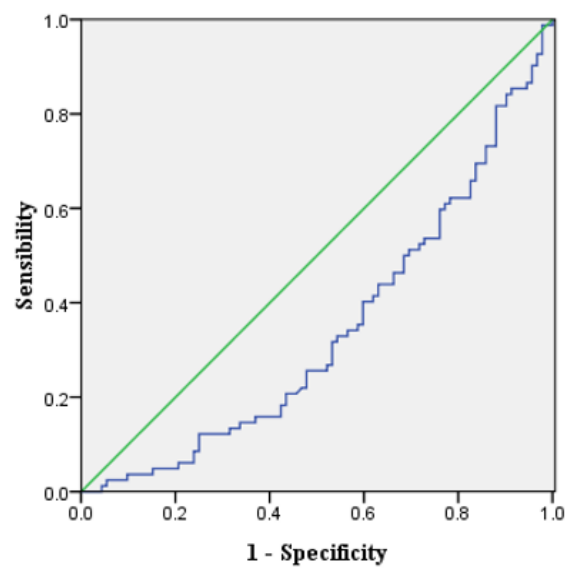

\section{ROC.2}

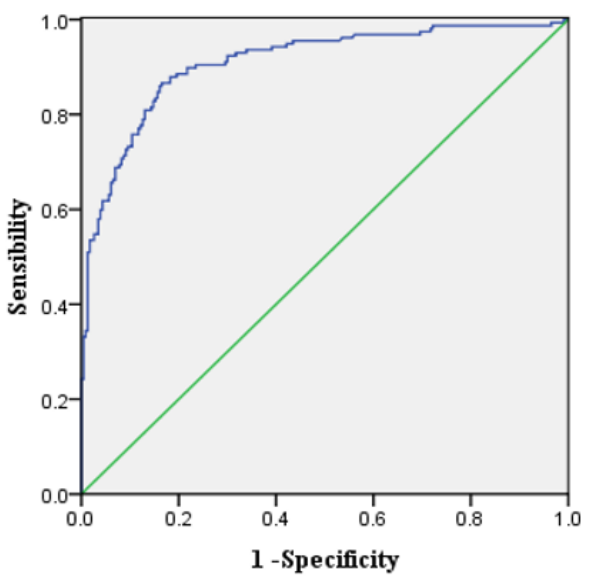

\section{ROC.4}

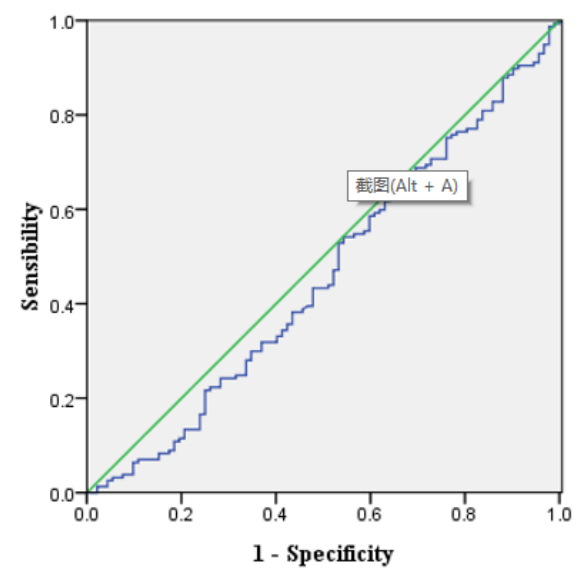

ROC.5

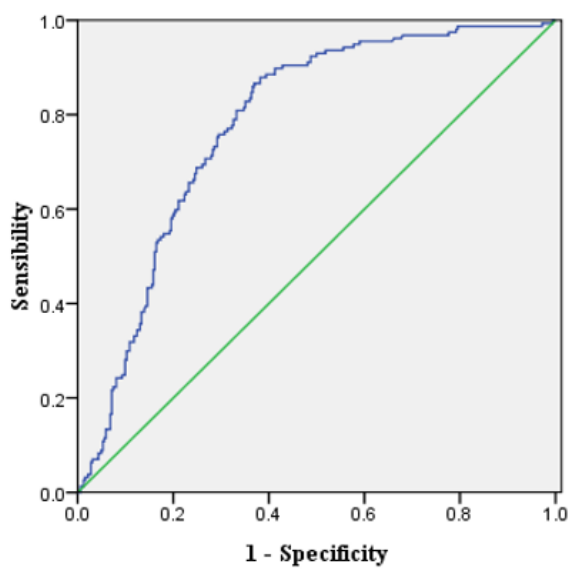

Figure 2

Five ROC curves of serum CC16 for diagnosing ARDS in critical care patients: ROC. 1 in the control group vs. the ARDS group; ROC. 2 in the control group vs. the ARDS group, ARDS+AKD group, and ARDS+CKD group; ROC.3 in the AKI group and CKD group vs. the ARDS group; ROC.4 in the AKI group and CKD group vs. the ARDS group, ARDS+AKD group, and ARDS+CKD group; ROC.5 in all groups. 

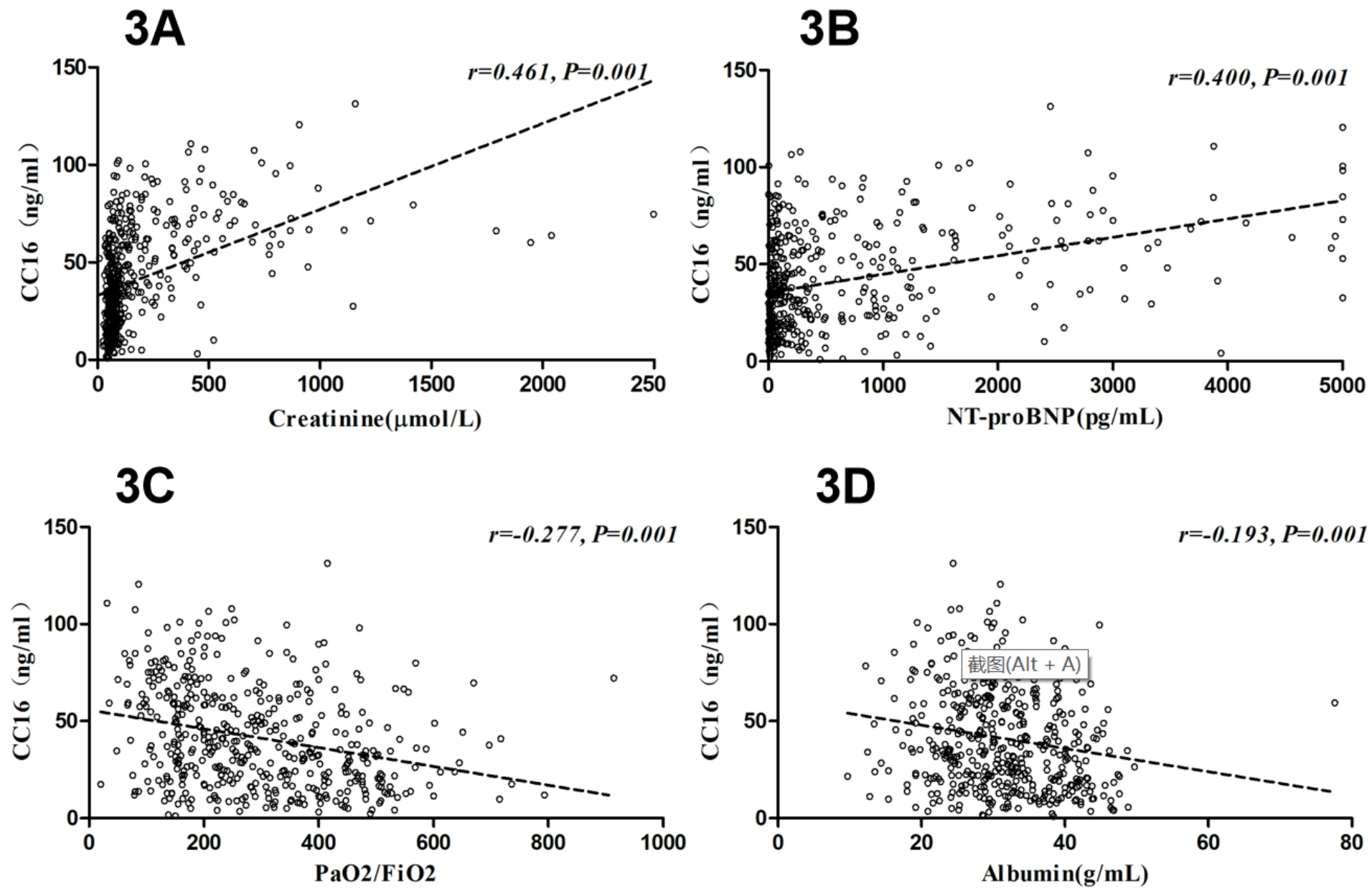

Figure 3

3A. A positive correlation between the serum $\mathrm{CC} 16$ levels and serum creatinine in all groups. 3B. A positive correlation between the serum CC16 levels and NT-proBNP in all groups; 3C. A negative correlation between the serum CC16 levels and PaO2/FiO2 in all groups. 3D. A negative correlation between the serum CC16 levels and albumin in all groups. 